\title{
Innovative Culture: An Intervention Strategy for Sustainable Growth in Changing Scenario
}

\author{
Muna Kalyani \\ Faculty, P.G. Department of Business Administration \\ Utkal University \\ Vani Vihar, Bhubaneswar, Orissa, India. \\ E-mail: dr.munakalyani@yahoo.com
}

Received: August 20, 2011

Accepted: September 25, 2011 Published: November 21, 2011

doi:10.5430/ijba.v2n4p84

URL: http://dx.doi.org/10.5430/ ijba.v2n4p84

\begin{abstract}
To-day's era is very hypercompetitive, a key feature of the new economy in the changing business scenario. The pace of change is increasing at an exponential rate. Continuous change and maintenance of high standards of quality products, services and processes have become prerequisites of the organization's success in to-day's competitive world. Organizations can rarely stand still for long. In highly competitive environment, where competition is global and innovation is continuous, change has become a core competency of organizations. Change refers to making things different. Innovation is a more specialized kind of change. All innovation involves change, but not all changes necessarily involve new ideas or lead to significant improvement or radical breakthroughs. Competitive climate requires organizations to institutionalize the process of innovation -to plant the seeds of innovations can utterly transform a scenario, involves the unfreezing-change-refreezing process. Innovation is not a thing that can be purchased or installed like a computer system. Rather it is a culture that must be adopted and nurtured which extracts values from assets old and new, and rejuvenates and revolutionizes industry, society and business. Innovation is an act of changing the established way of doing things, the ability to turn knowledge into value and link emerging technologies with emerging markets and is about bringing creative new ideas to life. The process involves the ways in which norms and values are set and practiced, holds innovative driven culture. This innovative culture can give competitive advantage; provided it is deeply rooted in the functional aspects of the organizations' culture, where the productive potential of people' knowledge and actions are guided and governed by the spirit and principles of OCTAPACE and innovative cultures. These cultures get into hyper drive mode to keep growth engine humming. The article examines this context and argues that organizations can use innovative culture as a strategic intervention for managing change for survival and growth.
\end{abstract}

Keywords: Institutionalization of Innovative Culture, Innovative Climate, Culture Drives Growth

\section{Introduction}

In the pre-liberalization era, national economy was isolated itself from the global economy, which led to the crippling of skills to a great extent. Now that the economy has opened up, a number of new players have emerged to grasp the opportunities. The current business environment is fraught with cut-throat competition and companies are clueless about how to combat domestic as well as global competition. The basic ideas around it is that companies compete with each other to offer values to the customers, and the ones that offer better values will be able to gain greater market-share which in turn, will lead to better profitability. The value creation process of competing companies should be analyzed to assess the relative advantages that each company enjoys. In this proactive mode, organizations tend to be innovative, focus on future markets and technologies, look at future customers, be constantly vigilant to capitalize on fleeting opportunities, and be prepared to make obsolete their own products. Even if it were to receive a setback, the organization seeks to identify signs of progress and evidences of innovative thinking. Innovative organizations are and able to take risks and are organized (Birdi and Walsh, 2007) for constant change. It puts knowledge to work on products, processes, technologies, and markets, and eventually on knowledge itself. Organizations regard innovation as the best way to leap-frog competition. This tends to look beyond the present and creates a future vision. They recognize a need even before the customers do and help create demand for new products. Innovation could take a variety of forms. It could die in realizing the hidden potential of the technological advancements in the industry before other do even. 
To succeed, an organization must gain and maintain an edge over its competitors-that is a firm must develop a competitive advantage that is a firm's ability to perform in one or more ways that competitors cannot or will not match. It is difficult to build sustainable competitive advantages. At best, they may be leverageable. A leverageable advantage is one that a firm can use as a springboard to new advantages, such as Microsoft has leveraged its operating system to Microsoft Office and then to networking applications. A firm hopes to endure, must be in the business of continuously innovating new values for new advantages while scanning and coping with the turbulent competitive environment. To-day's era is hypercompetitive, a key feature of the new economy in the changing business scenario.

\section{Innovative Culture}

Innovative culture is the key to competitive advantage and a vital strategy for survival and growth of the firm. Today's competitive climate requires organizations to institutionalize the process of innovation- to plant the seeds of innovation can utterly transform a scenario, involves the destruction of old -and sometimes comfortable and perfectly good -ways of doing business. As innovation is the initiation or adoption of new or improved, or changed products, services, process, procedures, or idea by an organization. The capacity to innovate (Andrew, Harold, Angle, and Poole, 1989) is central to the ability of an organization to adapt to changes in its environment. All innovation revolves around change -but not all change is innovative. Organizational innovation encourages individuals to think independently and creatively in applying personal knowledge to organizational challenges. Therefore, organization requires innovative cultures that support new ideas, processes and generally new ways of doing business and its underlying values act as driving force. Growth creates a need for structure, strategy, discipline and organization changes which can strain the culture of creativity that is so vital to future success. To sustain competitive advantage, organizations need to institutionalize the innovation process; they need to create an internal environment where creative thinking is central to their values, assumptions and actions. Organizations should set the groundwork for innovation, initiate any required operational changes to foster the right culture, and guide the organizations through the recurring periods of changes. In promoting an innovative culture, organizations foster a framework of innovative culture. The Figure 1 explains that creating the right foundation, enhancing operations to foster innovation, and managing the ongoing change, institutionalization and stabilization, and periodic audit and evaluation are important steps in transforming an organization into an engine of innovation. Sustaining an innovative culture requires organizations to create an environment (Clegg, Robinson, Wall and Wood, 2008) where creative thinking is the corporate values, actions, and assumptions. Employees need to seek new opportunities, accept risk, collaborate, and commit themselves to the organization beyond self-interest. This action is determined by the organization's culture-the shared values, beliefs, and norms that provide a corporate identity and guide how employees think, feel and act. Managers within high growth organizations need to be active in creating an environment that guides and promotes such actions (Birdi, 2005).

To sustain competitiveness, organizations need to pursue a strategy of differentiation. Executing this strategy requires a culture of non-stop innovation. Instead of relying on the expertise and creative skills of the few individuals, organization must institutionalize innovation just as any other key process within the organization. It follows a five- step approach to fostering an innovative culture:

\subsection{Create the Required Foundation}

Assess the role innovation currently plays in the organization. Current customs, traditions, and general way of doing things are largely due to what it has done before and the degree of success it has had with those endeavors. It is required to make necessary adjustments to organization goals and culture, and redefine the roles, functions, and responsibilities of the leaders.

\subsection{Enhance Operations to Foster Innovation}

Create an environment and organization structure that empowers employees and promotes the collaboration required to generate and implement new ideas. A culture consisting of openness, collaboration, trust, authenticity, proactive, autonomy, confrontation, and experimentation is required to make innovation culture operational.

\subsection{Manage the Ongoing Change}

Create a team to guide and manage the ongoing change process. It will unfreeze inappropriate, irrelevant, inadequateness and move to a new desirable state.

\subsection{Institutionalization and Stabilization}

By institutionalization is meant making the change a permanent part of an organization, and by stabilization meant making the permanent change part into a natural part of an organization's working style. The former is more structural, and the latter more processual. 


\subsection{Periodic Audit and Evaluation}

Periodic audit and systematic evaluation may be based on continuous feedback. This step is required to know what difficulties people are experiencing in implementing and what results it produces for the organization, so that the necessary supports in this case can be provided.

Adhering, developing and enriching the framework will foster an innovative culture. Innovative culture is a capability to sustain against many difficulties and challenges. It provides the energy needed to function well and it becomes a survival strategy (Peter, 2002), when managed properly. The road to innovation lies in the ability to impact new knowledge and action to company manpower and in the application of that knowledge and actions. These should be used for new ways of thinking, and as a stepping stone to creativity and toward change and innovation. Motivation is one of the more fundamental axioms of innovation, that people's readiness and commitment for creativity and innovation, depend on creating a felt need for it. This involves making people so dissatisfied with the status quo that they are motivated to try new work processes, services, technologies or ways of behaving. Creating such dissatisfaction can be difficult but not impossible. Generally, people and organizations need to experience deep levels of hurt before they will seriously undertake meaningful change. It is required to sensitize organizations to pressure for it. Just as individual creativity requires that people are motivated to do what it takes to be creative. Innovation requires that organizations have the kind of cultures that encourage innovation. When top executives fail to promote a vision of innovation and accept the status quo, change is unlikely. However, at firms such as Microsoft, where leaders envision innovation as being part of the natural order of the things, is not surprising that innovative efforts constantly are underway. Efforts involve creating a vision of what people want the organization to look like or become. Generally, a vision describes the core values and purpose that guide the organization as well as an envisioned future toward which innovation is directed. The vision also can energize commitment to change by providing people with a common goal and a compelling rationale for why innovation is necessary (Chatman, 2002) and worth the effort. Developing a vision of innovation is heavily driven by people's values and preferences for what the organization should look like and how it should function. The envisioned innovation represents people's ideas, fantasies, or dreams of what they would like the organization to look like or become in the process of innovating new, new and new. Here, are some important tips for fostering a very congenial and conducive creativity and innovative culture. These are some characteristics that, in aggregate, capture the essence of innovative culture.

\subsubsection{Openness}

All the members of organization should feel free to express their ideas, opinions and feelings to each other irrespective of their ranks. They have no barriers to such expression. They are encouraged to express and are heard. People are creative, curious, artistically, sensitive, imaginative, better performers, flexible, willing to listen to new ideas and to change their own ideas, beliefs and attitudes in response to new information. They play for funs and relaxation, rather than to exhibit their superiority at any cost.

\subsubsection{Collaboration}

It is the culture, where people become eager to help each other. They are governed by larger goals, humanity and spirit of sacrifice for the sake of each other. Team spirit, group dynamics and cohesiveness are of the high order. Collaborative relationships lead to new and innovative ideas and solutions among the people.

\subsubsection{Trust}

A culture, which is built on the basis of trust and trustworthiness, where none will act opportunistically. In this culture, people believe each other and act on the basis of verbal instructions without having to wait for written instructions. Trust develops due to faith in the integrity of the other and the belief that person would act consistently. Integrity denotes total honesty without any underhand activities. Consistency refers to words and actions matching each other. Competence and loyalty are also integral to trust.

\subsubsection{Authenticity}

Organization members speak the truth fearlessly and keep up promises made. They do what they say. They never make false promises, just to please others. If they make promises, they put all efforts to implement their promises.

\subsubsection{Proactive}

A proactive culture encourages everyone to take initiative and make things happen. New activities and new ways of doing things are encouraged. People are introducing continual changes so as to bring about a better fit between the firm and its environment. They anticipate events, initiate actions and take control of the organization's destiny. 


\subsubsection{Autonomy}

People are having discretion and control over job-related decisions. There is freedom and independence in scheduling the work and determining the procedures to be used to complete the work. People make their own decisions rather than rely on detailed instructions from boss or procedure manuals. It appears to be fundamental in building a sense of responsibility at work.

\subsubsection{Confrontation}

It is the culture, where problems are diagnosed, confronted and solved collectively or individually. Every senior sees developing subordinates as his responsibility, seniors support their subordinates and juniors respect their seniors. Problems, mistakes and difficult situations are handled with learning orientations. Participation is encouraged. Ever incident is treated as a learning opportunity. People have a sense of satisfaction from their work. They feel that they are cared for and have a sense of belonging. They discuss issues with very little fear of hurting each other. Even if one may have to hurt the other, the issue is handled and not put under the carpet.

\subsubsection{Experimentation}

It is a kind of culture, where new ideas, new ways of doing things and take new decisions are applied and encouraged to initiating an improving a product, process, or service. Here, success and failure both are rewarded and encouraged, it supports people who try something. This also characterized risk taking culture. No risk no growth and development. Without experimentation, there is very little scope for renewal, rejuvenation of life. Experimentation leads to innovations.

Above these tips are consisting the OCTAPACE culture, highly oriented towards creativity and innovative culture when institutionalized. Each of these exists on a continuum from low to high. When these are intensely held and widely shared will exhibit high degree of creative and innovative culture. Innovation is a people process. It happens when people work together on a challenge that energizes them in an open environment of trust and respect, in which mistakes are considered learning events and everyone understands what value is being created for whom (Miller \& Friesen, 1982). An innovative organizational culture is one in which continuous improvement through the generation and implementation of ideas in all parts of the organization is the norm. It is not defined as something that a small minority are charged with doing (e.g. those in R\&D) with the results appearing at fixed times. Having an innovative culture should result in all employees being motivated and confident enough to continually try new things out. A prerequisite is that employees should be equipped with the right types of knowledge, skills and motivation to both effectively generate and implement new ideas. However, innovation will only flourish if the work environment is congenial of these efforts. This means employees must be given opportunities to explore, investigate and experiment and management should provide support through active encouragement of employees. The growth of an innovative culture can also be fostered by a variety of activities, these are, Integrating Research and Development Section confirms that investment in R\&D can promote innovation but the development of an innovation culture depends on ensuring that any designated R\&D department is fully integrated with other functions such as production and marketing. As well as focusing on fundamental discoveries, product changes, technological processes, research and development should be defined so it encompasses improvements in organizational processes; Research also has shown that organizations that benchmark their operations internally and externally, tend to be more innovative (Kotter, 1995). Organizations should benchmark themselves explicitly in terms of their innovation processes and outcomes. Involvement of customers and feedback from customers represents a major source of ideas for improving existing products or services, or developing new products and services and providing an opportunity for them to comment, can supply an organization with invaluable information on, for instance, the quality, usefulness, or price of products or services. Selecting people who are likely to be innovative can also foster an innovative culture. Research has uncovered four key traits that make for innovative people: openness to frequent change; active championing of change; unstructured approaches to work; and a preference to try doing things differently and allowing risk-taking leads a large number of ideas must be generated in order to produce one successful one, and that the implementation of ideas is often not right first time. An innovation culture should reflect this by showing a tolerance for errors and risk-taking, and rewarding effort as well as outcomes. There also needs to be an element of learning from any mistakes that are made by investigating regular reviews. A reinforcement system for innovation providing employees with rewards for their innovation activities is an important issue. Financial rewards can be useful, but research suggests that recognition from peers and superiors is especially important and that employees will perform even more creatively if motivated by the work itself, rather than by rewards or punishments (Taylor, 1995). An organization can develop this type of intrinsic motivation by encouraging employees to explore ideas that they find personally exciting, reinforcing feelings of personal competence and creating an environment where people can freely exchange ideas and explore areas of mutual interest. Training and development for creativity and innovation On the assumption that creativity is a skill that can be learned, creativity courses that cover 
opportunity finding, problem definition, idea generation, idea evaluation and idea implementation can confirm for effective. They signal that innovation is important and provides useful tools and ideas for employees. Yet, as with other types of training, there will be little long-term impact if the work environment to which employees return does not give them the support and freedom to express, develop and apply their ideas. Developing a learning culture; is a key element of an innovative culture and then the active encouragement of employees in continuous learning and development. By providing a wide variety of opportunities for learning, organizations expose their employees to a greater variety of stimuli, enhance their motivation to learn new things, create the knowledge and skills for them to develop and work with new innovations. Involving and empowering employees, encouraging employee participation in decision making are likely to lead to more successful innovations. This is especially the case where changes in ways of working are concerned. If strong representative structures exist, then involving representatives such as trade union officials in the innovation process is recommended. At an individual level, formal idea capturing schemes can also enable valuable contributions, and shown that it is vital to the effectiveness of such schemes to give feedback to employees. Furthermore, if employees do not think creativity is expected, making creativity a formal requirement of the work role can itself improve the degree of innovation shown. More generally, empowering employees by developing responsibility for organizing and managing work to individuals or teams encourages innovation. Job enrichment initiatives and self-managing work groups has shown that it is through the increased learning opportunities that such initiatives provide that most gains in productivity and quality arise. Providing the opportunity for employees to implement ideas, and involving them in the design of new work practices from the start, will enhance the effects of empowerment. Growing managers support to innovation of employees, and the line management support are linked to greater creativity of employees, especially with respect to the implementation of ideas ,and managers who are supportive of innovation they help employees learn how to share their knowledge and experience; they act as role models; they enhance employee motivation and confidence by giving supportive encouragement and feedback; and they nurture an environment in which employees feel they can be open and challenge even their supervisors' ideas. Supportive management thus underpins the other practices, without which they are unlikely to create an innovation culture. Strong leadership also ensures that they are used in the integrated way that an innovation culture would appear in the organization. The Institute of Work Psychology (IWP, 2007) has been conducting research in this area, and it has become apparent that a holistic approach is needed to initiate and sustain innovation in organisations. How such a culture is developed? Research conducted by IWP and others have highlighted some of the means by which this culture can be grown by selecting innovative employees; training for creativity and innovation; developing a learning culture; empowering employees; setting up idea capture schemes; developing managers to support the innovation of others; making creativity a requirement of the job; improving employee participation in decision-making; having appropriate reward systems for innovation; allowing risk-taking as an acceptable mode of practice; encouraging investment in research and development; and benchmarking.

To succeed, an organization must gain and maintain an edge over its competitors- a status achieved by an organization through intensely shared understanding by organization members. Sustaining an environment that will foster the ongoing creation of new and innovative ideas is a difficult task. Constant innovation is a hallmark of successful growth. Staying ahead of the competition requires a certain threshold of inventiveness, at the individual, group, and organization levels. Growth creates a need for structure and control, managed approach to risk, and an influx of new talent appropriate for subsequent stages of organizational development (Michael \& Charles,2002). Innovation is the lifeblood of every growth organization. Competitors will look to erode market position on the basis of price, product performance, customer service, and intangibles such as brand. Growth requires constant innovation-a progressive momentum, once disrupted, is difficult to regain. This is because the goal of innovation is to lead to products that generate above average returns. Innovation must be undertaken not just for its sake, but with the purpose of bringing measurable value through revenue and profitability enhancements (Hanson and Schneider, 1997). Innovative practices today become even more central role in building and achieving long-term competitive advantage. Organizations can gain and maintain sustained competitive advantage through creative and innovative culture which is a scarce resource, characterized by following criteria:

1. The resources must be of value.

2. The resources must be rare.

3. The resources must be difficult to imitate.

4. The resources must be organized.

5. The resources must be committed to deliver.

6. The resources must be responsive to market.

7. The resources must be strategic.

8. The cost leadership and product differentiation strategy must be greatly preferred and widely valued. 


\section{The Main Findings and Implications}

Use of innovative culture as intervention strategy for sustainable growth, take competitive advantages in changing business scenario while managing change. These are as follow:

1. Constant innovation is a hallmark of successful growth-staying ahead of the competition requires inventiveness at the individual, group, and organizational levels. As organizations grow, market demands and competition can force them to maintain a culture of nonstop innovation. Sustaining an innovative culture requires companies to create environments where creative thinking is central to corporate values, actions, and assumptions. Innovative organizations require employees who seek new opportunities, accept risk, collaborate well with others, and commit themselves to the organization. Innovative organizations also require leaders that will work to create those kinds of environments and will guide and promote innovative behavior continuously.

2. More and more, today's competitive climate requires organizations to institutionalize the process of innovation - to plant the seeds of creativity that could utterly transform a business to a greater sustainability. Creativity necessarily involves the destruction of old - and sometimes comfortable and perfectly good - ways of doing business. But for companies willing to take the risk - and for leaders committed to building innovative cultures - the first requirement is to understand the creative process, and the second is to commit to policies that support the creative process, it holds the potential for a renewed capability to thrive.

3. Instead of creating a capacity to simply respond to change, an innovation capability creates the type of change that simultaneously allows the organization to adapt to the world around it and also influences the world around it to adapt as well. An innovation capability is not a change neutralizer-it's a change maker. It's also natural. All are innovators by nature. In organizations, innovation can be developed into a practice and skills that are honed by the practitioners over time to reach the desired conditioning. To sustain competitive advantage, organizations must institutionalize their innovation process by creating an environment in which creative thinking is central to their values, assumptions, and actions.

4. The goal of innovation is to develop values for products or services that generate above-average returns as incremental capital. These returns allow organizations to re-invest in activities designed to give them a competitive advantage in the marketplace. When the innovation cycle is disrupted, organizations do not have this incremental capital base and, therefore, have to fund innovation-related activities with capital initially allocated for other purposes.

5. As companies grow, their leadership teams must manage increasingly complex organizations while maintaining a commitment to innovation. To do this, companies need to assess the state of their innovation and find means to enhance and foster it. Organizations need to focus innovation-related activities around the three principal elements of organizational corporate culture: core values, beliefs, and norms. Core values are principles that help human resources make decisions about what is important for the organizations. Beliefs are the shared views of what is right and wrong. Norms are the operating rules that determine acceptable employee behavior. A single set of core values, beliefs, and norms will focus the entire work- force on a set of common goals oriented towards innovations

6. An important role of a organizational leadership is to communicate and reinforce the core values, beliefs, and norms of organizational corporate culture and also serve as role models to the employees who look to them to provide inspiration, support for their ideas, and the guidance required to excel.

7. Creativity is the force behind innovation. Innovative achievements are the product of employees who have the right expertise, can think creatively about problems that arise, and are motivated to persevere through the discovery process.

8. In order to foster a culture of innovation, companies need to motivate their employees with rewards, recognition, and empowerment. Creating a true feeling of empowerment among employees is vital to fostering a culture of innovation. Assigning ownership of activities and giving employees the authority to make appropriate decisions are key motivational tactics. Organizations can empower their employees by encouraging divergent thinking, listening to them and being open to new ideas, and ensuring that they have the information and resources they need to follow through with their new ideas.

9. Empowerment does not mean simply handing over control. Freedom and authority must be complemented with accountability, management discipline, and feedback. To be effective, an innovative culture must be focused on achieving the results and deriving economic values outlined in the business strategy.

10. An organization's reward system must be designed to encourage innovation. Employees will be apprehensive of innovative activities if they perceive that they will be exposed to considerable personal risk. A truly innovative culture must make employees aware that the failure of a new idea or initiative to fulfill all expectations will not affect their 
position within the firm. In cases were expectations are not realized, it is important to emphasize the lessons that were learned.

11. Promoting a creative and innovative culture may require adjustment to an organization's internal and external operations. Organizations need to create a management team to oversee innovation and to communicate expectations to employees. It is also important to create a series of milestones to be used to gauge the progress toward a more innovative culture. A firm's leadership team has an important role in advocating the organizational changes required to sustain innovation. Employees need to understand that change is routine. Therefore companies need to create a change management team dedicated to the change process. The change management team's primary responsibility is to obtain organization-wide support for the change effort. This begins with clearly communicating the need for change. The team then needs to ensure that all projects are aligned with any changes in direction, and make sure that there are no inconsistencies in the practices expected and those performed. The change management team should also be given the authority to allocate resources to specific strategic areas and to terminate projects that are deemed unnecessary.

12. Transforming a company into an engine of innovation is a time-intensive process. By articulating clear short-term goals and measuring progress companies can communicate evidence of success to help maintain momentum behind the change effort. Given the unpredictable nature of innovation, companies may find it difficult to meet their objectives. Organizations may have to invest more time or money than expected into activities before their full benefits can be realized. Companies must be prepared to modify their plans and communicate setbacks and adjustments as required.

13. Human resources are a large reservoir of potential and can be strategically developed, utilized, controlled and conditioned innovativeness to a great extent for achieving growth, competitiveness and excellence in changing business scenario

\section{Conclusion}

Transforming an organization into an engine of innovation is time-intensive process. A great deal of time- consuming work is necessary to develop new idea into a marketable product or service. It is possible in a culture that attributes a high importance to openness and the willingness to cooperate, flexibility and the willingness to adapt needs to also aim at and be able to reduce fears and build trust-in words and deeds. It needs to tolerate friction and conflicts at and between all levels and encourage them, and it has to put all actors in the position to manage and solve such conflicts. This also includes the creation of risk awareness and the setting of boundaries; employees and manager need to be put into the position to be able to judge the relevance of innovative ideas and their boundaries in a realistic way. If this fails, entrepreneurial courage and the willingness to take risk quickly turn into recklessness. Still, a culture of innovation first and foremost requires a culture of trust. Establishing it often constitutes a process during which different and changing mechanisms and tools prove to be of value. They need to be institutionalized lasting and convincingly, continuously checked against their utilizability and adapted if necessary. There is nothing more detrimental than a mentality based on the formulas for past successes without permanent checks. Innovative culture is emotional and intellectual energy that fuels the journey to the future growth and success.

\section{Reference}

Anderson, J., and Markides, C. (2007). Strategic Innovation At the Base of the Pyramid, MIT Sloan Management Review, Fall, Vol.49, No. 1, 86-88.

Amabile, T. M. (1998). How to Kill Creativity, Harvard Business Review, September-October,78-84.

Andrew, H., Van de Ven, H. L., Angle, and Mabel, S. P. (1989). Research in the Management of Innovation, Cambridge, MA: Ballinger/ Harper \& Row, 6-7.

Arad, S., Hanson, M.A., and Schneider, R.J. (1997). A framework for the study of relationships between organisational characteristics and organisational behaviour, The Journal of Creative Behaviour, 31, 1, p42-58.

Birdi, K. (2005). No idea? Evaluating the effectiveness of creativity training. Journal of European Industrial Training, 29(2), 102-111. http://dx.doi.org/10.1108/03090590510585073

Birdi, K. (2007). A lighthouse in the desert? Evaluating the effectiveness of creativity training on employee innovation, Journal of Creative Behavior, 41(4), 249-270.

Birdi, K., Denyer, D., Munir, K., Neely, A. \& Prabhu, J. (2003). Post Porter: Where Does The UK Go From Here? Summary report from the AIM Management Research Forum. London: AIM. 
Birdi, K. (2007). Learning Organizations. In S.Rogelberg (Ed) Encyclopedia of Industrial/Organizational Psychology. Sage Press. p449-450

Birdi, K., Allan, C., \& Warr, P.B. (1997). Correlates and perceived outcomes of four types of employee development activity. Journal of Applied Psychology, 82(6), 845-857. http://dx.doi.org/10.1037/0021-9010.82.6.845

Birdi, K., Clegg, C., Patterson, M., Robinson, A., Stride, C., Wall, T and Wood, S. (2008). The impact of human resource and operational management practices on company productivity: A longitudinal study. Personnel Psychology, 61, 467-501. http://dx.doi.org/10.1111/j.1744-6570.2008.00136.x

Birdi, K., Denyer, D., Munir, K., Neely, A., \& Prabhu, J. (2003). Post Porter: Where Does The UK Go From Here? Summary report from the AIM Management Research Forum. London: Advanced Institute for Management (AIM).

Birdi, K., Pennington, J.\& Zapf, D. (1997). Ageing and errors in computer-based work: An observational field study. Journal of Occupational and Organizational Psychology, 70, 35-47. http://dx.doi.org/10.1111/j.2044-8325.1997.tb00629.x

Birdi, K., Wood, S. \& Patterson, M. (2007). Learning to perform? A comparison of learning practices and organisational performance in profit- and non-profit-making sectors in the UK. International Journal of Training and Development, 11 (4), 265-281. http://dx.doi.org/10.1111/j.1468-2419.2007.00285.x

Birdi, K.S., Warr, P.B. \& Oswald, A.J. (1995). Age differences in three components of employee well-being, Applied Psychology: An International Review, 44(4), 345-373.

Burke, M., Holman, D. \& Birdi, K. (2006). A Walk on the Safe Side: The Implications of Learning Theory for Developing Effective Safety and Health Training. In G. Hodgkinson \& K. Ford (Eds). The International Review of Industrial and Organizational Psychology, Vol 21, Chichester: John Wiley and Sons. http://dx.doi.org/10.1002/9780470696378.ch1

Cappelli, P. (2002). Corporate Culture as a Contributor to Growth, Growth Connections. [Online] Available:www.growth-connections.com

Cha, S., Chatman, J. (2002). Mastering Leadership: Culture of Growth, Financial Times, November.

Christensen, C. M., Overdorf, M. (2000). Meeting the Challenge of Disruptive Change, Harvard Business Review, January.

Cummings, A., Oldham, G. (1997). Enhancing Creativity: Managing Work Contexts for the High Potential Employee, California Management Review, September.

Miller, D., and Friesen, P. H. (1982). Innovation in Conservative and Entrepreneurial Firms: Two Models of Strategic Momentum, Strategic Management Journal -3, 1-2. http://dx.doi.org/10.1002/smj.4250030102

Elwood, S. B. (1984). Meeting the Competitive Challenge, Homewood, IL: Richard Irvin, 16-19.

Haybyrne, J. (2002). Cynicism Undermines Corporate Culture. South China Morning Post, January.

Kanter, R.M. (1999) The Enduring Skills of Change Leaders. Leader to Leader Institute.

Kashani, K. (2007). Diversification into New Markets. Growth Connections. [Online] Available: www.growth-connections.com

Kanter, R.M. (1999). The Enduring Skills of Change Leaders, Leader to Leader Institute, DTT Analysis.

Kashyap, P., and Raut, C. (2006).The Rural Marketing Book, Text/Practice, New Delhi, Dream Tech Press.

Kotter, J. P. (1995). Leading Change:Why Transformation Efforts Fail. Harvard Business Review, January.

Leseure, M., Birdi, K., Bauer, J., Denyer, D., \& Neely, A. (2004). Adoption of Promising Practice: A systematic review of the evidence. AIM literature review for UK Department of Trade and Industry Innovation Review. AIM Research, London Business School: London.

Leseure, M.J., Bauer, J., Birdi, K., Neely, A.D. \& Denyer, D. (2004). Adoption of Promising Practices: A Systematic Review of the Evidence. International Journal of Management Reviews, Vol. 5-6, pp. 169-190. http://dx.doi.org/10.1111/j.1460-8545.2004.00102.x

Lewin, A. (2006). Fostering Innovation in a Company, Growth Connections. [Online] Available: www.growth-connections.com last accessed on July 28, 2009. 
Magadley, W., \& Birdi, K. (2006). What is a creativity retreat centre? Competency and Emotional Intelligence, 13(4), 43-44.

Norfolk, T., Birdi, K. \& Walsh, D. (2007). The role of empathy in establishing rapport in the consultation: a new model. Medical Education, 41, 690-697. http://dx.doi.org/10.1111/j.1365-2923.2007.02789.x

Pandit, R. V. (2005), What's Next for Tata Group: An Interview With Its Chairman, McKinsey Quarterly, 4, 60-69.

Robinson, M., Sparrow, P., Clegg, C. \& Birdi, K. (2005). Design engineering competencies: Future requirements and predicted changes in the forthcoming decade. Design Studies, 26, 123-153. http://dx.doi.org/10.1016/j.destud.2004.09.004

Robinson, M., Sparrow, P., Clegg, C. \& Birdi, K. (2007). Forecasting future competency requirements: A three-phase methodology. Personnel Review, 36 (1), 66-90. http://dx.doi.org/10.1108/00483480710716722

Shipton, H., Fay, D., West, M., Patterson, M. \& Birdi, K. (2005). Managing people to promote innovation. Creativity and Innovation Management, 14(2), 118 - 128. http://dx.doi.org/10.1111/j.1467-8691.2005.00332.x

Shipton, H., West, M.A., Dawson, J., Patterson, M. \& Birdi, K. (2006). HRM as a predictor of innovation. Human Resource Management Journal, 16(1), 3-27. http://dx.doi.org/10.1111/j.1748-8583.2006.00002.x

Sutton, R. I, (2002). Weird Ideas that Spark Innovation. MIT Sloan Management Review, Winter.

Taylor, W. C. (1995). At VeriFone It’s a Dog's Life (and They Love It!), Fast Company, November.

Totterdell, P., Leach, D., Birdi, K., Clegg, C., \& Wall, T. (2002). An investigation of the contents and consequences of major organizational innovations, International Journal of Innovation Management, 6, $343-368$. http://dx.doi.org/10.1142/S1363919602000641

Tushman, M. L., O’Reilly, C. A. (2002). Winning Through Innovation, Harvard Business School Press.

Warr, P. and Birdi, K. (1998). Employee age and voluntary development activity, International Journal of Training and Development, 2(3), 190-204. http://dx.doi.org/10.1111/1468-2419.00047

Warr, P., Allan, C. \& Birdi, K. (1999). Predicting three levels of training outcome. Journal of Occupational and Organizational Psychology, 72, 351-375. http://dx.doi.org/10.1348/096317999166725

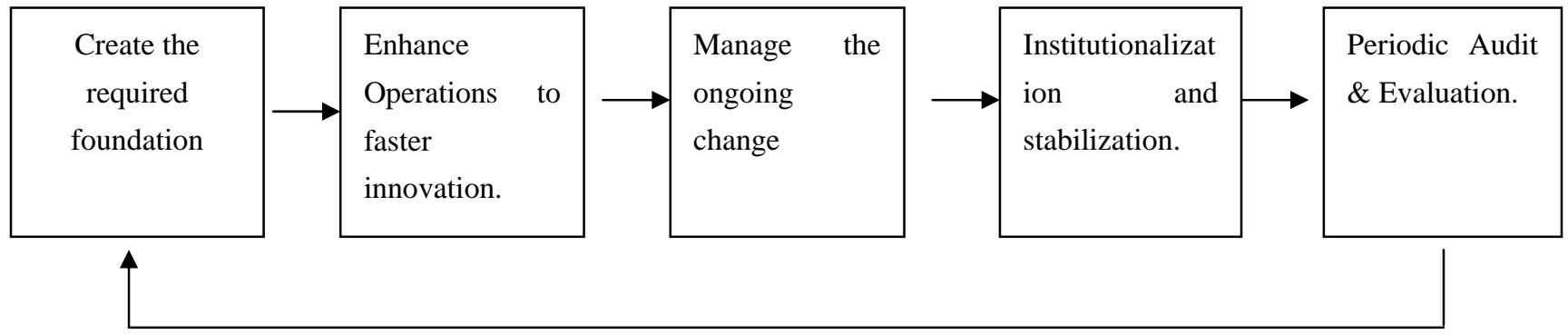

\section{Feed back}

Figure 1. A frame work for fostering an innovative culture 